\title{
An Assessment of 3G Mobile Service Acceptance in Bangladesh
}

\author{
Tajmary Mahfuz and Subhenur Latif \\ Department of Computer Science and Engineering \\ Daffodil International University \\ 102, Shukrabad, Dhaka, Bangladesh
}

\begin{abstract}
This paper aims to find out the key factors influencing mobile users to adopt 3Gtechnology and affecting the subscriber's feedback while using third generation (3G) mobile services that are available for one year in Bangladesh. An interesting fact that motivated this research was the significant low rate of 3G service usage among mobile operators in Bangladesh though we get the completely opposite picture worldwide. To examine the user acceptance and to depict user behavioral pattern, data were collected from 200 respondents through a survey. The analysis was done into two categories: one was in general and the other one was department based. The results of the study revealed the user intention, awareness, attitude, expectation, key $3 \mathrm{G}$ service usage etc. The findings have future implications for existing as well as newly arrived service providers who have very recently started their journey. Considering these identified factors would provide the directions for telecom operators to achieve high rate of $3 \mathrm{G}$ service adoption and to provide more successful 3Gservices.However, the study covered a limited area where those findings are applicable. The result of this study might be helpful for the telecom operators while targeting the $3 \mathrm{G}$ subscriber market and also for the future research on this field.
\end{abstract} pattern

Keywords-Awareness; Adoption; $3 G$ mobile service; usage

\section{INTRODUCTION}

$3 \mathrm{G}$ was a long awaited thing that created high expectations among the mobile operators before its arrival in Bangladesh. There has been a steady growth in worldwide $3 \mathrm{G}$ mobile adoption. To shine with the $3 \mathrm{G}$ growing world, Bangladesh had started its journey of $3 \mathrm{G}$ on 14 October, 2012 by Teletalk, the government-owned telecom operator. About a year later, the number of subscribers has not been increased significantly as expected (around 4lac).Despite the availability of 3G services, basic mobile services are still the most popular services. Bangladesh held its first $3 \mathrm{G}$ spectrum auction in September, 2013 where four more telecom operators had been awarded 3G spectrum (Grameen Phone, Airtel, Banglalink and Robi) along with Teletalk.

The development of mobile services - or mobile commerce or mobile Internet - has been intense for years but adoption has not progressed as expected [13]. Many studies have investigated the user acceptance and success factor of mobile services in general, and 3G in particular [1]. Research on $3 \mathrm{G}$ technology acceptance in Bangladesh will therefore be extremely worthy in providing useful information, especially at this early stage of $3 \mathrm{G}$ mobile internet development and implementation in this country. So far, no such research has been done on this area. Hence, the purpose of this study is to examine factors affecting subscribers' acceptance towards using $3 \mathrm{G}$ mobile service. From this study, the mobile service providers could use the findings to understand user demand and behavior.

\section{LITERATURE REVIEW}

Recently 3G services are tremendously developing. This section reviews literature related to current usage, customer behavior, customer segmentation, acceptance and features that affect usage in various countries, although some authors have presented their interpretations regarding the future of $3 \mathrm{G}$ and its prospective. $3 \mathrm{G}$ services were first adopted in Japan in 2001. Deepti and Ajay present the patterns, awareness and adoption of $3 \mathrm{~g}$ users among young generations in Botswana [1]. Research conducted in Malaysia by suki [2], suggests that, to adopt $3 \mathrm{G}$ mobile services, the $3 \mathrm{G}$ mobile telecommunication companies need to lift consumer's intention.

User's of $3 \mathrm{G}$ mobile services need to be offered with more diverse and entertaining ways of communicating, which are at the same time easily accessible and convenient to use. Kim [3] recognize various services of $3 \mathrm{G}$ like video calling, on line $\mathrm{TV}$, global roaming and advance services via the mobile multimedia Internet for magnetizing mobile phone subscribers. Pagani [7] focused the reasons of adoption 3G and ranked "Price" as third after "usefulness" and "ease of use",

According to Greek market perspective, about the charges of 3G, Indrawati, S. Murugesan, and M. A Raman Chatziagapis [8] infer that mobile services may pledge revenue growth for the operators, but the features of usefulness, security and especially the price of the mobile services have to be considered seriously in order for future adoption. Pagani [7], Indrawati et al [8] have also found price as a determinant factor for $3 \mathrm{G}$ mobile services adoption.

Moreover, modern services are enhances by using $3 \mathrm{G}$ services. Like smart home, wireless intelligence video system. [5], [6].

Several facilities have been provided by $3 \mathrm{G}$ users. It allows simultaneous use of speech and data services [4]. The main services of $3 \mathrm{G}$ like high speed data transmission, entertainment and e-payment are interrupted due to lack of infrastructure in Japan, developing countries in Asia, Africa or even some parts of US. High subscription charges, earnings affordability, mobile network coverage and 
telecommunication transportation to maintain all these activities classified with regard to findings is difficult for developing or even some developed countries in the world [9]. Li-Chen Cheng, Li-Min Sun, [10] proposed some diverse varieties of brand new application services to attract the new $3 \mathrm{G}$ subscribers. Despite of various benefits provided by the $3 \mathrm{G}$ services, it has not received great adoption rate as expected.

Margheaita [11] sketches a model of consumer adoption of third generation mobile multimedia services, by a qualitative exploratory study and empirically test the proposed model on the Italian market. Moreover Ong [12] investigates the factors affecting the purpose to adopt $3 \mathrm{G}$ services among the university students in Malaysia as they expected to be the group with great potential to adopt 3 Gservices.

\section{METHODOLOGY}

In this paper we have focused on the grounds, demands of young generation who are actually concerned on new technology like 3G. Our work suggests that there is great deal of research on adoption of mobile phones and mobile related services. This study intended at reviewing the a wareness and usage of new $3 \mathrm{G}$ mobile services like high speed internet [14], mobile device features and services [15], like video calling, online TV, etc., usage of mobile applications [8, and 16] and usages of mobile data services [17].

Also emphasis on behavioral intention to use [13], and approach towards $3 \mathrm{G}$ mobile services in Bangladesh. A large scale of subscribers have adopted some basic mobile services such as SMS, ring tones, icons, wall papers, logos, caller tunes[18] and these services became their everyday's life styles.

Adoption patterns, present situation, problems and requirements of the $3 \mathrm{G}$ subscriber's have been tried to discuss in this paper and have sketched the overall scenario by reviewing the responses of the $3 \mathrm{G}$ usages.

\section{DATA COLlection AND ANALysis}

In total, 200 students of Faculty of Science and IT from first to fourth year of the graduation participated in this study, by completing the questionnaire. The age range was from 20 to 25 years. Each of the participants was $3 \mathrm{G}$ user having a $3 \mathrm{G}$ supported cell phone. Since for providing 3Gtechnology, there was only one available telecom operator during the time of concerned research, each respondent was a subscriber of that operator.

There were two aspects of the research work. One part of focus was the general data analysis where the concerned area was the whole user domain. The other aspect was department wise analysis where each department was individually taken as area of interest and data were organized according to the departments. Through questionnaires and the statistically analysis has been by using SPSS.

\section{A. General data analysis}

$70 \%$ users used mobile internet before adopting $3 \mathrm{G}$ while $30 \%$ users started using mobile internet with $3 \mathrm{G}$.

Based on the use of internet connection, two categories of 3G users found. Category-1 users have both internet connection at home and $3 \mathrm{G}$ connection (65\%) and Category-2 $(35 \%)$ users do not have other internet connection that is only 3G users. Among Category-1 users, 38.5\% do browsing, 76.9\% do uploading and 92.3\% do downloading (Fig:1).

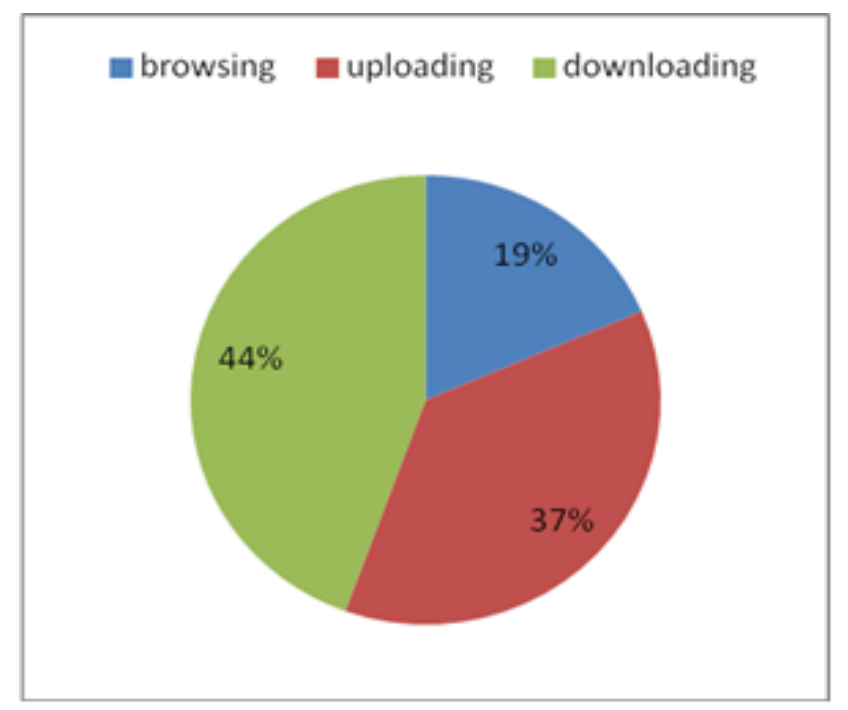

Fig. 1. using different services at home by using $3 \mathrm{~g}$ connection.

Among the reasons behind adopting 3G, 95\% users use 3G for better services, $45 \%$ respondents use $3 \mathrm{G}$ influenced by their friends and the rest $25 \%$ had other reasons. Of all $3 \mathrm{G}$ services, the most used service was speed of data transfer $(89.5 \%)$, followed by gaming application(78.9\%), then video calling(36.8\%)and lastly mobile $T V(31.6 \%)$. For barriers, poor network coverage came out as the main problem $(100 \%)$ of using 3G.High rate of charging rated as second (90\%) followed by insufficient service provider (50\%) and lack of high speed (35\%).Another point was user expectations or desired facilities of 3G. Most desired service was strong network coverage (100\%), followed by low charge rate $(95 \%)$ and high speed $(50 \%)$.

\section{B. Department-wise analysis:}

Four departments were considered for analysis: Computer Science and Engineering (CSE), Electrical and Electronic Engineering (EEE), Textile Engineering (TE) and Software Engineering (SWE. The scenarios of department wise $3 \mathrm{G}$ users were: CSE-40\%, TE-30\%, EEE-15\% and SWE$15 \%$.Onthe point of use of mobile internet before $3 \mathrm{G}$, department wise user behavior had been recognized. The results were: For CSE department, $42.9 \%$ had used, 33.3\% had not used. For TE department, $21.4 \%$ had used, $50 \%$ had not SWE and TE. The scenarios of department wise $3 \mathrm{G}$ users used. For EEE, used-14.3\%, not used-16.7\%. For SWE, $21.4 \%$ hadused. Then we figured out department wise most frequently used services(Table 3,4). Table 3 shows most frequently used services of individual departments. For CSE department, the highest used service was both speed of data transfer(75\%) and gaming application(75\%). For all the three departments of TE, EEE and SWE, speed of data trans ferranked as the top most used service. 
TABLE I. DEPARTMENT-WISE MOST FREQUENTLY USED SERVICES ON 3G

\begin{tabular}{|l|l|c|}
\hline Department & Most used Services & Response \% \\
\hline \multirow{4}{*}{ CSE } & Speed of data transfer & 75 \\
\cline { 2 - 3 } & Mobile TV & 12.5 \\
\cline { 2 - 3 } & Video calling & 25 \\
\cline { 2 - 3 } & Gaming application & 75 \\
\hline \multirow{5}{*}{ TE } & Speed of data transfer & 100 \\
\cline { 2 - 3 } & Mobile TV & 50 \\
\cline { 2 - 3 } & Video calling & 50 \\
\cline { 2 - 3 } & Gaming application & 83.3 \\
\hline \multirow{5}{*}{ EEE } & Speed of data transfer & 100 \\
\cline { 2 - 3 } & Mobile TV & 33.3 \\
\cline { 2 - 3 } & Video calling & 33.3 \\
\cline { 2 - 3 } & Gaming application & 100 \\
\hline \multirow{5}{*}{ SWE } & Speed of data transfer & 100 \\
\cline { 2 - 3 } & Mobile TV & 50 \\
\cline { 2 - 3 } & Video calling & 50 \\
\cline { 2 - 3 } & Gaming application & 50 \\
\hline
\end{tabular}

TABLE II. DEPARTMENT-WISE PROBLEMS ENCOUNTERED BY THE USERS

\begin{tabular}{|l|l|l|}
\hline Department & Most used Services & Response \% \\
\hline \multirow{4}{*}{ CSE } & High charging rate & 87.5 \\
\cline { 2 - 3 } & Poor network coverage & 100 \\
\cline { 2 - 3 } & Lack of high speed & 50 \\
\cline { 2 - 3 } & Insufficient service provider & 75 \\
\hline \multirow{5}{*}{ EE } & High charging rate & 83.3 \\
\cline { 2 - 3 } & Poor network coverage & 100 \\
\cline { 2 - 3 } & Lack of high speed & 33.3 \\
\cline { 2 - 3 } & Insufficient service provider & 33.3 \\
\hline \multirow{5}{*}{ SWE } & High charging rate & 100 \\
\cline { 2 - 3 } & Poor network coverage & 100 \\
\cline { 2 - 3 } & Lack of high speed & 33.3 \\
\cline { 2 - 3 } & Insufficient service provider & 33.3 \\
\hline & High charging rate & 100 \\
\cline { 2 - 3 } & Poor network coverage & 100 \\
\cline { 2 - 3 } & Insufficient service provider & 33.3 \\
\hline
\end{tabular}

\section{FINDINGS AND DisCUSSION}

From the empirical analysis, we have found some interesting results leading to informative facts.

Though many people in Bangladesh have heard about 3G from media and other sources, the total number of $3 \mathrm{G}$ users is very poor. The structured and unstructured interviews with $3 \mathrm{G}$ nonusers revealed the reasons. One main factor for this is the insufficiency of service provider since at first only one telecom operator was permitted for providing $3 \mathrm{G}$ services. Another strong reason is; the short time period for $3 \mathrm{G}$ service availability. Therefore, it is understandable that as like as the arrival of any new technology, the rate of $3 \mathrm{G}$ adoption that is the number of subscribers may increase with time.

In the case of adopting $3 \mathrm{G}$, variations in user background showed different outcomes. The rate of $3 \mathrm{G}$ adoption is quite high for those who previously used mobile internet comparing to the non users. While digging for reason, it came out that upgrading to higher standards or versions happens naturally for an existing system user. On the contrary, this is not the case for a fresher as it demands to deal with a completely new thing.

Another observation of user behavioral analysis is that the users who were using other internet connection along with $3 \mathrm{G}$ had chosen 'downloading' as their most prioritized activity compared to others. Now the question arises that why those users are keeping additional internet connection when they can use 3 G.Price is an issue here. Users have to pay more for unlimited data volume in $3 \mathrm{G}$ where there are more options in cheaper rate.

$3 \mathrm{G}$ provides many attractive and additional features like as video calling, mobile TV and of course, better services than the existing system e.g. high speed internet. All these things allure users to subscribe to $3 \mathrm{G}$. The users of $3 \mathrm{G}$ voted high speed data transfer as their most used service. Poor network coverage was the biggest barrier that interrupts the enjoyment of using $3 \mathrm{G}$ services at great extent. Therefore, it is no wonder that the most desired service of $3 \mathrm{G}$ subscribers is the strong network coverage.

\section{LiMITATIONS AND FUTURE SCOPE}

Our study has some limitations. All the respondents were all most same age group and came from almost same background, which is one of the limitations. The study is based on a limited number of respondents which is a limitation. To interpret the behaviors of all mobile phone users, the result cannot be generalized. Despite these limitations, however, this study provides insights into the adoption behavior of $3 \mathrm{G}$ services. For future analysis, bigger sampling data would be considered. Comparison based study could be conducted on the pattern changes in $3 \mathrm{G}$ service usage in time. Also, uses of high technology based on $3 \mathrm{G}$ like smart home, could be perform in future study.

\section{CONCLUSION}

In our research paper, we have sketched the adoption scenario of a new technology called $3 \mathrm{G}$. The penetration of the usage and adoption of $3 \mathrm{G}$ mobile services has been done in this research. The recent addition of four new telecom operators in $3 \mathrm{G}$ market of Bangladesh has created the competitive and challenging field in service providing. This phenomenon demands to adopt the correct marketing strategy and business model to catch on the potential customers. In this perspective, the findings of this study provide the directions. The service providers should concentrate on minimizing the negative factors at highest possible rate like poor network coverage that badly affect the user. Exploitation of cost and providing high speed constantly are some key demands that needed to be addressed.

\section{REFERENCES}

[1] Deepti Garg, Ajay K. Garg," An Assessment of Awareness, Usage Pattern and Adoptionof 3G Mobile Services in Botswana," International Journal of Computer Theory and Engineering, Vol. 3, No. 4, August 2011.

[2] Suki,"Third generation (3G) mobile service acceptance:Evidencefrom Malaysia,"http://www.academicjournals.org/AJBM.

[3] Y. Kim, "Estimation of consumer preferences on new telecommunications services: IMT-2000 service in Korea" Information Economics and Policy, vol.17. pp.73-84, Jan 2005. 
[4] Dr. Sudha Singh, Dr. D. K. Singh, Dr. M. K. Singh and Sujeet Kumar Singh [4],'The Forecasting Of 3g Market In India Based On Revised Technology Acceptance Model," International Journal of NextGeneration Networks (IJNGN) Vol.2, No.2, June 2010.

[5] Gwang Jun Kim, Chang Soo Jang, Chan Ho Yoon, Seung Jin Jang and Jin Woo Lee,"The Implementation of Smart Home System Based on 3G and ZigBee in Wireless Network Systems,"International Journal of Smart Home Vol. 7, No. 3, May, 2013.

[6] Qigui ZHANG, Yu CHEN," Design of Wireless Intelligent Video Surveillance System Based on 3G Network," http://iaesjournal.com/online/index.php/TELKOMNIKA/issue/view/169, vol 12, No 1,2013.

[7] M. Pagani, "Determinants of Adoption of Third Generation Mobile Multimedia Services," Journal of Interactive Marketing, Vol. 18(3), pp.46-59. Summer $2004 \quad$ [Online] Available ,http://www.interscience.wiley.com

[8] Indrawati, S. Murugesan, and M. A Raman "New Conceptual Model of Mobile Multimedia Services (MMS) and 3G Network Adoption in Indonesia," International Journal of Information Science and Management Special Issue January / June, 2010.

[9] S.T. Abu, "Empirical analysis of global diffusion of 3G mobile phones:a cross-cultural review," Discussion Paper No. AIDP0906. Graduate School of Applied Informatics, University of Hyogo, Japan 2010

[10] Li-Chen Cheng, Li-Min Sun," Exploring consumer adoption of new services by analyzing the behavior of $3 \mathrm{G}$ subscribers: An empirical case study," Electronic Commerce Research and Applications 11 (2012) 891002011 .www.elsevier.com/locate/ecra.
[11] MargheaitaPagani,"depart of adoption of third generation mobile multimedia servies,"Journal of Interactive Marketing ,Vol. 18,No. 3,Summer 2004.

[12] J. W. Ong, Yew-Siang Poong and Tuan Hock Ng, "3G Services Adoption among University Students:Diffusion of Innovation Theory," Communications of the IBIMA Volume 3, 2008.

[13] ChristerCarlsson, KaarinaHyvönen, Petteri Repo and Pirkko Walden," Adoption of Mobile Services across Different Technologies,"18th Bled e Conference e Integration in Action, Bled, Slovenia, June 6 - 8, 2005.

[14] P. Jiang "Consumer Adoption of Mobile Internet Services: An Exploratory Study," Journal of Promotion Management, vol. 15 (3), pp.418-454, 2009.

[15] A. A.Economides, and A. Grousopoulou, "Students' thoughts about the importance and costs of their mobile devices' features andservices," Telematics and Informatics, vol. 26 (1), pp. 57-84, 2009.

[16] H. Verkasalo, C. López-Nicolás, F. J. Molina-Castillo, H. Bouwman: "Analysis of users and non-users of smartphone applications,"Telematics and Informatics, vol. 27(3): pp. 242-255, 2010.

[17] J. Harno, "Impact of $3 \mathrm{G}$ and beyond technology development and pricing on mobile data service provisioning, usage and diffusion," Telematics and informatics, vol. 27 (3), pp. 269-282, August 2010.

[18] C. Carlsson, J. Carlsson, K. Hyvönen, J. Puhakainen and P. Walden, "Adoption of Mobile Devices/Services - Searching for Answers withthe UTAUT", in Proc. of the 39th Hawaii International Conference on System Sciences, HICSS, 2006. 